\title{
Advances in the Prediction of the Bearing Capacity of Road Flexible Pavements using GPR
}

\author{
Fabio Tosti ${ }^{1}$, Luca Bianchini Ciampoli ${ }^{2}$, Fabrizio D'Amico ${ }^{2}$, Amir M. Alani ${ }^{1}$ \\ ${ }^{1}$ School of Computing and Engineering, University of West London (UWL) \\ St Mary's Road, Ealing, W5 5RF, London, UK \\ Fabio.Tosti@uwl.ac.uk; Amir.Alani@uwl.ac.uk \\ ${ }^{2}$ Department of Engineering, Roma Tre University \\ Via Vito Volterra 62, 00146 Rome, Italy \\ luca.bianchiniciampoli@uniroma3.it; fabrizio.damico@uniroma3.it
}

\begin{abstract}
This work proposes an experimental-based model for the assessment of the bearing capacity of road-flexible pavements using ground-penetrating radar (GPR - 2 GHz horn antenna) and the Curviameter non-destructive testing (NDT) methods. It is known that the identification of early decay and loss of bearing capacity is a major challenge for effective maintenance of roads and the implementation of pavement management systems (PMSs). To this effect, a time-efficient methodology based on a quantitative modelling of road bearing capacity is developed in this study. The viability of using a GPR system in combination with the Curviameter NDT equipment is also proven.
\end{abstract}

Keywords-ground-penetrating radar (GPR), Curviameter, road-flexible pavements, road bearing capacity, experimentalbased model; pavement management systems (PMS)

\section{INTRODUCTION}

Reduction of accidents is a major priority and a challenging task to achieve for road administrators and government authorities [1]. The relation between pavement decay and frequency of accidents is well-known [2]. In this regard, an extensive and time-efficient assessment of roads at the network level is crucial to prioritise interventions and reduce the likelihood of accidents.

Most of the damage in road-flexible pavements occur where stiffness of the asphalt and load-bearing layers is low. To this extent, an effective assessment of the strength and deformation properties of these layers can help to identify the most critical sections [3].

Bearing capacity of subgrades can be evaluated by on-site [4], [5] and laboratory [6] tests. Although these methods are very reliable, they are time-consuming and usually carried out on a few road sections. Hence, they can provide only partial information on the pavement stiffness of a certain road network. In addition, these methods may have driving safety implications as they require partial or full closure of an infrastructure.

Within this context, applications of non-destructive testing (NDT) methods for the assessment of the mechanical properties of pavements have increased over the last decades. Within the class of deflection-based methods, the falling weight deflectometer (FWD) [7] is used for the assessment of integrated flexible pavement structures. Light falling weight deflectometer (LFWD) is instead employed for construction quality control purposes of unbound materials [8], [9], although applications on bound layers are also reported in the literature [10], [11]. The main limitation of these methods is that data can be collected only at discrete points, thereby affecting time and cost of the operations. To meet this requirement, fully equipped non-destructive testing lorries have been developed at a later stage for the evaluation of the mechanical properties of road pavements at traffic speed. Within these types of NDT equipment, the Curviameter [12] and the traffic speed deflectometer (TSD) [13] are worthy of mention. A limitation of the Curviameter is related to the relatively-limited traffic speed of acquisition (i.e., $18 \mathrm{~km} / \mathrm{h}$ ) along with the impossibility to take measurements in curves with horizontal radii lower than $40 \mathrm{~m}$. In regard to the TSD acquisition method, measurements can be affected by several internal and external factors such as, calibration and quality assurance procedures, wind and temperature change during the acquisition, pavement roughness and tire-pavement interaction [14].

Although all of the above deflection-based methods are very reliable, they require integration with other NDT methods (e.g., ground-penetrating radar (GPR)) in order to provide an ultimate data output (e.g., stiffness of a certain road layer). This also implies to carry out an acquisition of the same road per every NDT employed in the process.

GPR is mostly used to collect information on the geometry of the road structure (i.e., the pavement layers) as well as the main physical properties. Successful applications of GPR have been reported across many disciplines including civil engineering [11], demining [15], archaeology [16], geology [17], glaciology [18] and many more. A general standard practice in highway engineering is to integrate measurements from a deflection-based equipment with geometric information from GPR. This allows a reliable estimation of the stiffness of the pavement layers using a back-calculation process.

In view of the above limitations, a faster and robust model for the estimation of the mechanical properties of flexible pavements based on data fusion from different acquisition methods is required. First modelling approaches were developed by [19], [3]. These methods related GPR data outputs with deflection-based information measured by 
LFWD and provided overall good results. A demonstration of the potential of GPR to be integrated with deflection-based data from a Curviameter is given in this study in an effort to provide a faster and reliable acquisition framework for implementation in pavement management systems (PMSs).

\section{AIMS AND OBJECTIVES}

This paper aims at providing a faster and robust GPRbased model for the estimation of the mechanical properties of road flexible pavements. To achieve this Aim, the main objective was to demonstrate the viability of integrating GPR data and deflection-based information collected using the Curviameter NDT method.

\section{METHODOLOGY}

The methodology used in this paper for the development of the prediction algorithm follows a multi-stage framework, consisting of the following steps:

- data analysis of the ground-truth data from the Curviameter;

- data analysis of the model input parameters from GPR;

- modelling of the prediction algorithm;

- data collection (on-field);

- model application

In terms of data analysis of the ground-truth data from the Curviameter, the following equation was taken as a robust indicator to represent the overall pavement stiffness:

$$
T_{z}=\sqrt{\frac{R_{c}}{D_{\max }}}
$$

where $T_{z}$ is the bearing capacity, and $R_{c}$ and $D_{\max }$ are the radius of curvature and the maximum deflection of the deflection bowl, respectively.

The overall thickness of the bitumen-bond layers (i.e., surface, binder and base layers) as well as an attenuation factor accounting for relevant reflections at the interface between the above-considered layers were taken into account as model input parameters from the GPR acquisitions.

The modelling step was developed following a multi-stage optimisation approach. This accounted for the use of: i) a scale factor, ii) a first-approximation bearing capacity at any abscissa point along the longitudinal direction of scanning $T_{z}^{*}(x)$, iii) a statistical analysis of the errors, and iv) a final optimised modelled value of bearing capacity $T_{z}^{\prime}$ (i.e., the input of the model).

Data collection and model application are discussed in the next paragraphs.

\section{SURVEY Site AND TESTING EQUIPMENT}

The above methodology was applied to a real-life rural road network located in the districts of Madrid and Guadalajara, Spain (Fig. 1). In more detail, three road stretches were surveyed in May 2015 using GPR and the Curviameter NDT equipment. The overall surveyed distance was approximatively $45 \mathrm{~km}$ long.

The investigated road infrastructures are two-lane rural all-purpose highways with a flexible pavement structure.

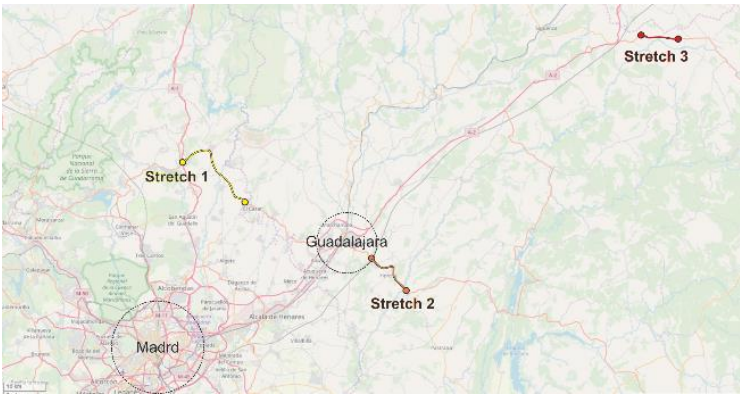

Fig. 1. The surveyed road network in the vicinity area of Madrid and Guadalajara, Spain.

Cores were extracted for calibration purposes across the entire investigated network with a spatial interval of $5 \mathrm{~km}$, i.e., a number of three cores for each road stretch. Table 1 shows the average thicknesses observed for the pavement layers.

In regard to the GPR equipment, a RIS Hi-Pave pulse radar system was coupled with a $2000 \mathrm{MHz}$ horn antenna. IDS GeoRadar (Part of Hexagon), also involved in the experimental activities, manufactured both the GPR system and the antenna.

The air-coupled antennas were hold at a constant height of approximatively $40 \mathrm{~cm}$ from the pavement. This was achieved by means of a non-dielectric support that was directly mounted onto an instrumented vehicle (Fig. 2). The overall system allowed to collect data at an average speed of $60 \mathrm{~km} / \mathrm{h}$. Values of the acquisition parameters used for the GPR investigations are summarised in Tab.2.

Deflection data were collected using the Curviameter nondestructive testing lorry provided by Euroconsult SA, that facilitated the experimental activities (Fig. 3).

Values of the acquisition parameters from the Curviameter equipment are reported in Tab. 3. In this regard, the productivity of the system allowed to measure a deflection bowl of $1 \mathrm{~m}$-depth, with a horizontal resolution of $5 \mathrm{~m}$. Furthermore, the equipment permitted dynamic measurements at an average speed of $18 \mathrm{~km} / \mathrm{h}$.

\section{MAIN RESUlTS AND SHORT DISCUSSION}

Results discussed in this Section refer to the application of the method described in Section III to the structural data for the Road Stretch 2 (see Tab. 1). In more detail, the surveyed road stretch is a $11 \mathrm{~km}$-long section of the N-320 Highway, located in the district of Madrid.

Tab. 1. Information on the pavement structures extracted from cores.

\begin{tabular}{lccr}
\hline Stretch & Wearing $(\mathrm{cm})$ & BB Base $(\mathrm{cm})$ & Gran. Base $(\mathrm{cm})$ \\
\hline 1 & 8 & 10 & N.A. \\
2 & 6 & 8 & 18 \\
3 & 10 & 15 & N.A. \\
\hline BB: bitumen-bond; Gran.: granular; N.A.: not available.
\end{tabular}

Tab. 2. GPR acquisition parameters.

\begin{tabular}{cccc}
\hline Freq. (MHz) & Time window (ns) & Spatial res. (m) & Samples \\
\hline 2000 & 15 & 0.0208 & 512 \\
\hline
\end{tabular}




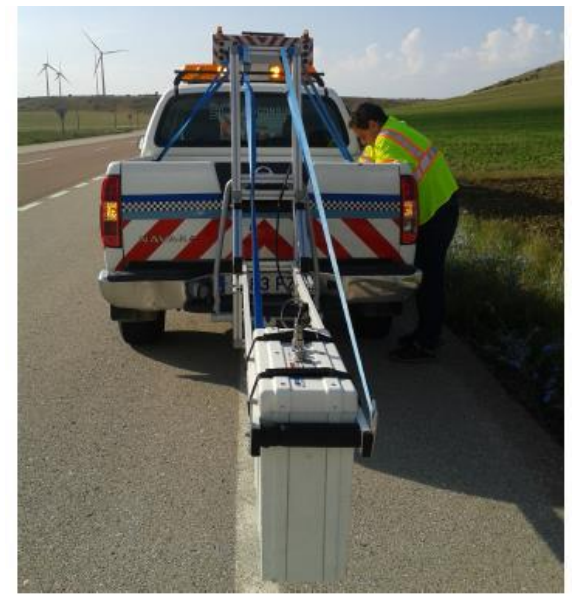

Fig. 2. The GPR equipment.

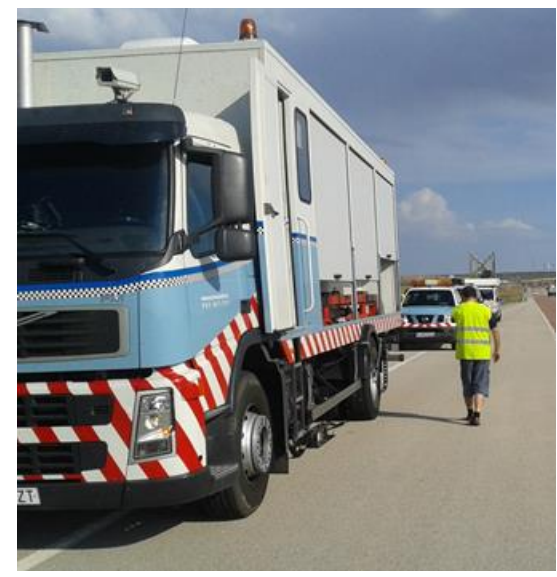

Fig. 3. The Curviameter non-destructive equipment.

Tab. 3. Curviameter acquisition parameters

\begin{tabular}{cccc}
\hline Load $(\mathrm{kN})$ & Speed $(\mathrm{km} / \mathrm{h})$ & Spatial res. $(\mathrm{m})$ & Depth \\
\hline 130 & 18 & 5 & 1 \\
\hline
\end{tabular}

According to the information gathered from cores and after a preliminary analysis of the GPR data, the road stretch was divided into two main sub-sections. These sections resulted to be homogenous in terms of pavement structure and main configuration. Calibration of the model parameters for these two sub-sections was performed on a randomly-selected percentage of $5 \%$ of the overall data.

In order to enhance the reliability of the model calibration stage, peak values of both the EM signal and deflections from the Curviameter were considered as outliers and excluded from the analyses. It was observed that these values were mainly due to the presence of small bridges and water drainage systems along the scanning direction.

The final optimised modelled value of bearing capacity $T_{z}^{\prime}$ was eventually compared with the measured value of bearing obtained from the Curviameter measurements (Fig. 4). Outputs have been reported for a set of randomly-selected kilometres over the entire inspected road stretch.

Comparison shows a very limited mismatching between predicted and measured bearing capacity values. To support this evidence, an average NMRSD value of $7 \%$ was observed, with a corresponding standard deviation of $3.7 \%$.
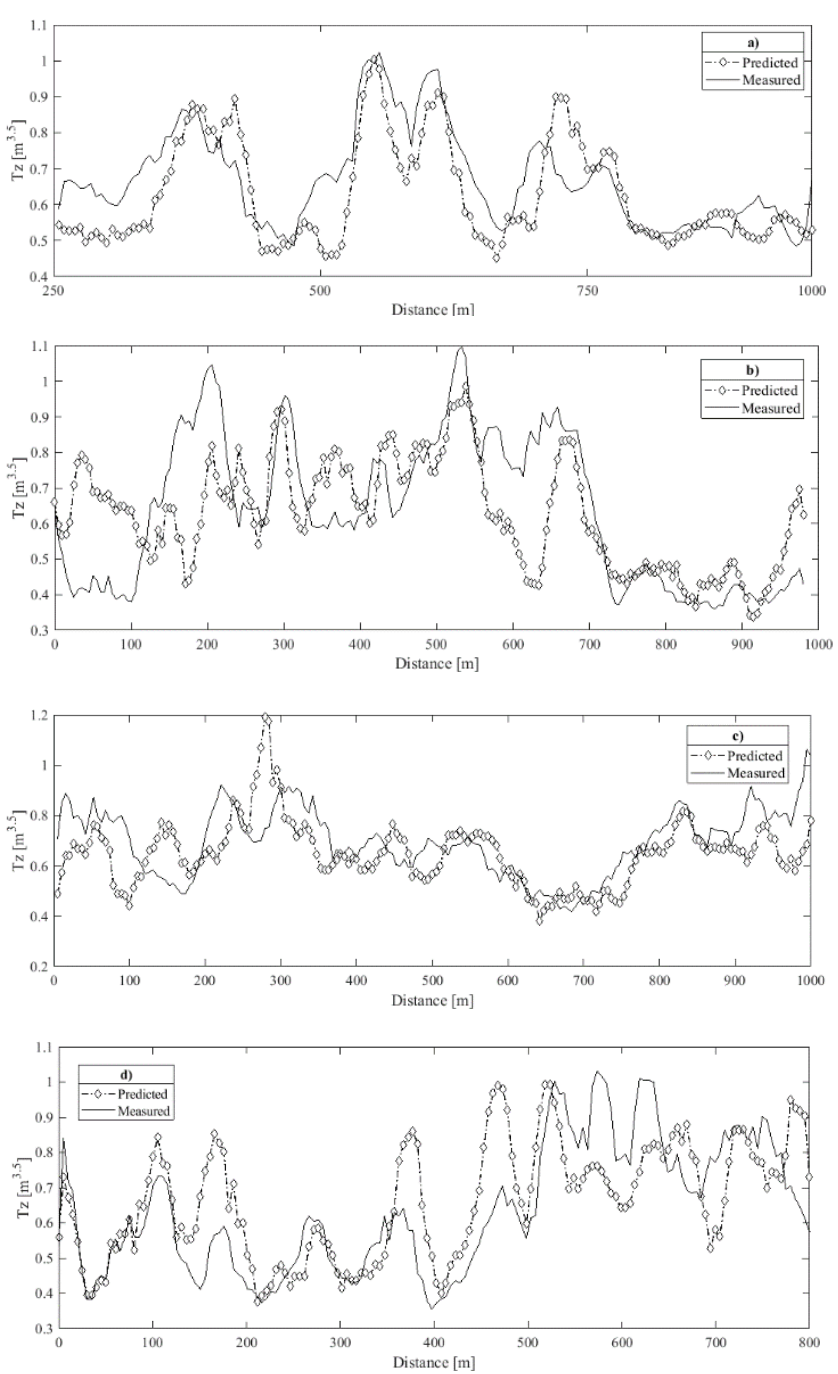

Fig. 4. The comparison between the output of the model and the measured bearing capacity for a) $\mathrm{km} 1, \mathrm{~b}) \mathrm{km} 6, \mathrm{c}) \mathrm{km} 8$ and d) $\mathrm{km} 11$.

\section{CONCLUSION}

This work reports an experimental-based model for the assessment of the bearing capacity of road-flexible pavements using ground-penetrating radar (GPR $-2 \mathrm{GHz}$ horn antenna) and the Curviameter non-destructive testing (NDT) methods. To this effect, a time-efficient multi-stage methodology based on an optimisation modelling of road bearing capacity is developed in this study.

To demonstrate the viability of the proposed approach, a real-life rural road network located in the districts of Madrid and Guadalajara, Spain, was surveyed for an overall distance of $45 \mathrm{~km}$. The investigated road infrastructures are two-lane rural all-purpose highways with a flexible pavement structure. For the sake of brevity, the paper reports only part of the results, all of which were related to the Road Stretch 1 (see Tab. 1).

The application of the model has proven to be very consistent with the ground-truth bearing capacity data obtained from the Curviameter. A very limited mismatching between predicted and observed bearing capacity values was in fact observed with an average NMRSD and standard deviation values of $7 \%$ and $3.7 \%$, respectively. 
It is important to emphasise the benefit of the proposed methodology for a faster data collection and the provision of critical information on the mechanical properties of flexible pavements for a potential use in pavement management systems (PMSs).

\section{ACKNOWLEDGMENTS}

The authors would like to express their sincere thanks to Mr. Spartaco Cera, from Roma Tre University, for the technical support provided during the tests, as well as to Ms. Gabriella Salerno, for the support provided with the data analysis. We are also grateful to IDS GeoRadar (Part of Hexagon) and Euroconsult SA for facilitating the tests on site.

\section{REFERENCES}

[1] Frangopol, D.M.; Liu, M. Maintenance and management of civil infrastructure based on condition, safety, optimization, and life-cycle cost. Struct. Infrastruct. Eng. 2007, 1, 29-41.

[2] S. Tighe, N. Li, L.C. Falls, R. Haas, Incorporating road safety into pavement management, Transp. Res. Rec. 1699 (2000) 1-10.

[3] F. Tosti, C. L. Bianchini, F. D'Amico, A. M. Alani and A. Benedetto, "An experimental-based model for the assessment of the mechanical properties of road pavements using ground-penetrating radar," Construction and Building Materials, vol. 165, pp. 966-974, 2018.

[4] ASTM D1195/D1195M-09, Standard test method for repetitive static plate load tests of soils and flexible pavement components, for use in evaluation and design of airport and highway pavements, ASTM International, West Conshohocken, PA., 2009.

[5] ASTM D4695-03, Standard Guide for General Pavement Deflection Measurements, ASTM International, West Conshohocken, PA, 2008.

[6] ASTM D4429-09a, Standard Test Method for CBR (California Bearing Ratio) of Soils in Place", ASTM International, West Conshohocken, PA, 2009.

[7] ASTM E2583-07, Standard Test Method for Measuring Deflections with a Light Weight Deflectometer (LWD)", ASTM International, West Conshohocken, PA., 2011.

[8] A. Benedetto, F. Tosti, L. Di Domenico, Elliptic model for prediction of deflections induced by a Light Falling Weight Deflectometer. J. Terramechanics 49 (1) (2012) 1-12.
[9] P.R. Fleming, M.W. Frost, J.P. Lambert, Review of lightweight deflectometer for routine in situ assessment of pavement material stiffness, Transp. Res. Rec., (2007) 80-87

[10] A. Benedetto, L. Pajewski, Eds. (2015), Civil Engineering Applications of Ground Penetrating Radar, Springer - Book Series: Springer Transactions in Civil and Environmental Engineering; doi: 10.1007/978-3-319-04813-0

[11] P.R. Fleming, M.W. Frost, J.P. Lambert, Review of lightweight deflectometer for routine in situ assessment of pavement material stiffness, Transp. Res. Rec., (2007) 80-87

[12] J.-M. Simonin, J.-L. Geffard, P. Hornych, Performance of deflection measurement equipment and data interpretation in France, International Symposium Non-Destructive Testing in Civil Engineering (NDT-CE) September 15-17, 2015, Berlin, Germany.

[13] A. Zofka, J. Sudyka, Traffic speed deflectometer (TSD) measurements for pavement evaluation, in Proc. of the International Symposium on Non-Destructive Testing in Civil Engineering (NDT-CE), Berlin, Germany, Sept. 15-17, 2015.

[14] A. Zofka, M. Graczyk, J. Rafa, Qualitative evaluation of stochastic factors affecting the Traffic Speed Deflectometer results, in Proc. of the Transportation Research Board 94th Annual Meeting, Washington DC, USA, Jan. 11-15, 2015.

[15] C. Bruschini, B. Gros, F. Guerne, P.-Y. Pièce, O. Carmona, Ground penetrating radar and imaging metal detector for antipersonnel mine detection, J. Appl. Geophys. 40 (1-3) (1998) 59-71.

[16] D. Goodman, Ground-penetrating radar simulation in engineering and archaeology, Geophysics 59 (2) (1994) 224-232.

[17] A.K. Benson, Applications of ground penetrating radar in assessing some geological hazards: examples of groundwater contamination, faults, cavities, J. Appl. Geophys. 33 (1-3) (1992) 177-193.

[18] L.A. Plewes, B. Hubbard, A review of the use of radio-echo sounding in glaciology, Progress Phys. Geography 25 (2) (2001) 203-236.

[19] F. Tosti, S. Adabi, L. Pajewski, G. Schettini, A. Benedetto, Large-scale analysis of dielectric and mechanical properties of pavement using GPR and LFWD, in Proc. of the 15th International Conference on Ground Penetrating Radar, Brussels, Belgium, Jun.-July 2014, pp. 868-873. 